\title{
Comparison of single versus fractionated dose of stereotactic radiotherapy for salvaging local failures of nasopharyngeal carcinoma: a matched-cohort analysis Daniel TT Chua*1, Shao-Xiong Wu ${ }^{2}$, Victor Lee ${ }^{1}$ and Janice Tsang ${ }^{1}$
}

\author{
Address: ${ }^{1}$ Departments of Clinical Oncology, The University of Hong Kong, Queen Mary Hospital, Hong Kong SAR, PR China and ${ }^{2}$ Department \\ of Radiation Oncology, Cancer Centre, Sun Yat-Sen University, Guangzhou, PR China \\ Email: Daniel TT Chua* - dttchua@hkucc.hku.hk; Shao-Xiong Wu - aba@aol.hk; Victor Lee - vhflee@hku.hk; \\ Janice Tsang - jwhtsang@hkucc.hku.hk \\ * Corresponding author
}

Published: 23 May 2009

Head \& Neck Oncology 2009, I:13 doi:10.1 I86/1758-3284-I-13
Received: 15 May 2009

Accepted: 23 May 2009

This article is available from: http://www.headandneckoncology.org/content/I/I/13

(C) 2009 Chua et al; licensee BioMed Central Ltd.

This is an Open Access article distributed under the terms of the Creative Commons Attribution License (http://creativecommons.org/licenses/by/2.0), which permits unrestricted use, distribution, and reproduction in any medium, provided the original work is properly cited.

\begin{abstract}
Background: wLocal failure is an important cause of morbidity and mortality in nasopharyngeal carcinoma (NPC). Although surgery or brachytherapy may be feasible in selected cases, most patients with local failure require external beam re-irradiation. Stereotactic radiation using single or multiple fractions have been employed in re-irradiation of NPC, but the optimal fractionation scheme and dose are not clear.
\end{abstract}

Methods: Records of 125 NPC patients who received salvage stereotactic radiation were reviewed. A matched-pair design was used to select patients with similar prognostic factors who received stereotactic re-irradiation using single fraction (SRS) or multiple fractions (SRM). Eightysix patients were selected with equal number in SRS and SRM groups. All patients were individually matched for failure type (persistent or recurrent), $r T$ stage ( $\mathrm{rTI}-2$ or $\mathrm{rT3}-4)$, and tumor volume ( $\leq$ $5 \mathrm{cc},>5-10 \mathrm{cc}$, or $>10 \mathrm{cc}$ ). Median dose was $12.5 \mathrm{~Gy}$ in single fraction by SRS, and $34 \mathrm{~Gy}$ in 2-6 fractions by SRM.

Results: Local control rate was better in SRM group although overall survival rates were similar. One- and 3-year local failure-free rates were $70 \%$ and $51 \%$ in SRS group compared with $91 \%$ and $83 \%$ in SRM group ( $P=0.003$ ). One- and 3 -year overall survival rates were $98 \%$ and $66 \%$ in SRS group compared with $78 \%$ and $61 \%$ in SRM group $(p=0.31)$. The differences in local control were mainly observed in recurrent or rT2-4 disease. Incidence of severe late complications was $33 \%$ in SRS group vs. $21 \%$ in SRM group, including brain necrosis (16\% vs. $12 \%$ ) and hemorrhage $(5 \%$ vs. $2 \%)$.

Conclusion: Our study showed that SRM was superior to SRS in salvaging local failures of NPC, especially in the treatment of recurrent and rT2-4 disease. In patient with local failure of NPC suitable for stereotactic re-iradiation, use of fractionated treatment is preferred. 


\section{Background}

Local recurrence is an important cause of treatment failure in nasopharyngeal carcinoma (NPC). Recent advances in radiotherapy planning and delivery and the use of concurrent chemo-radiotherapy have significantly reduced the incidence of local failure in NPC, and most modern series reported an overall 5-year local control rate of 76-91\% [15]. In patients with advanced $\mathrm{T}$ stage and/or bulky tumor, local failure however remains an important cause of morbidity and mortality. Although surgical resection or brachytherapy can be used as salvage treatment in selected cases of local failure, most patients require external re-irradiation for retreatment of NPC. Conventional two-dimensional radiotherapy planning and delivery was commonly used in the past for external reirradiation of NPC, but treatment outcome was generally poor with a high incidence of severe late complications [6-8]. Three-dimensional conformal radiotherapy can achieve better target coverage and sparing of critical structures, but the incidence of late complication still appears to be high after reirradiation of NPC even with the use of conformal radiotherapy [9]. The technique of stereotactic localization of target and treatment delivery has also been employed in salvaging local failures of NPC, which includes the use of single fraction of stereotactic re-irradiation (SRS) or multiple fractions of stereotactic re-irradiation (SRM). These two techniques were employed at Queen Mary Hospital in Hong Kong and Sun Yat Sen University Cancer Center in Guangzhou for re-irradiation of NPC, with adoption of SRS in the former center and SRM in the latter one. Different techniques were adopted at the two centers due to institutional preference and logistic reasons such as available machine time. Since there were no prospective studies comparing stereotactic re-irradiation using SRS or SRM, we conducted a retrospective study to compare the outcome of patients treated by SRS and SRT using a matched-pair design.

\section{Methods}

\section{Selection of matched pair}

This was a retrospective study comparing the outcome of patients with locally recurrent NPC treated by SRS and SRM. Records of patients who received SRS or SRM as salvage treatment of NPC at Queen Mary Hospital in Hong Kong and Sun Yat-Sen University in Guangzhou were reviewed for inclusion into the study. A matched pair study was used to select and analyze patients with similar prognostic factors from the two treatment groups. Only those patients who satisfied the following criteria were included in the matching process: history of poorly differentiated or undifferentiated carcinoma of the nasopharynx, completed a course of radical radiotherapy with or without chemotherapy, and histological proven local failure or progression of local disease documented by serial imaging. Patients who received SRS or SRM as a planned boost after external radiotherapy and those with disease elsewhere were excluded.

Individual patients from the two treatment groups were matched for important prognostic factors identified from previous studies: type of local failure (persistent disease, defined as local failure that occurred within 6 months of completion of primary radiotherapy, vs. recurrent disease, defined as local failure that occurred beyond 6 months of completion of primary radiotherapy), retreatment $\mathrm{T}$ stage (rT1-2 vs. rT3-4), and tumor volume ( $\leq 5 \mathrm{cc}$ vs. $>5-10 \mathrm{cc}$ vs. $>10 \mathrm{cc}$ ). Each patient in the SRS group was matched with another patient in the SRM group with respect to these factors, and only patients that were matched for all 3 factors were included in the study.

\section{Patient characteristics}

Forty-eight patients received SRS at Queen Mary Hospital from January 1994 to June 2005 and 90 patients received SRM at Sun Yat-Sen University Cancer 2005 and 90 patients received SRM at Sun Yat-Sen University Cancer Center from September 1999 to December 2005 for isolated local failures of NPC. Thirteen patients were not included in the matching process due to presence of synchronous nodal disease in 2 and distant metastases in 3, and the use of SRS/SRM as planned boost in 8 . The remaining 125 patients were included in the matching process, and 43 matched pairs were selected for comparison. All these patients had undifferentiated type of nasopharyngeal carcinoma and were staged by computed tomography and magnetic resonance imaging at the time of diagnosis. First course of radiotherapy was delivered using megavoltage radiotherapy with conventional twodimensional technique, and the dose to nasopharynx was 66-70 Gy. About 23\% of patients from Queen Mary Hospital and 26\% from Sun Yat-Sen University Cancer Center also received adjunctive chemotherapy. All patients were jointly assessed by radiation oncologist and head and neck surgeon for other options including nasopharyngectomy and brachytherapy prior to stereotactic radiotherapy. Table 1 summarizes the patient characteristics of matched SRS and SRM groups.

\section{SRS and SRM treatment}

SRS was performed at Queen Mary Hospital using the commercial XKnife system (Radionics, Burlington, MA) to deliver multiple non-coplanar arcs of photon to the target with a modified $6 \mathrm{MV}$ linear accelerator (Varian Clinac 600C, Milpitas, CA.). Head immobilization and target localization were performed with the Brown-RobertsWells head frame and stereotaxic system (Radionics, Burlington, MA). Axial contrast CT with a slice thickness of 2.5 to $3 \mathrm{~mm}$ was performed for treatment planning, supplemented by axial contrast MR with a slice thickness of 3 $\mathrm{mm}$ in rT3-4 disease. Target volume was defined as any 
Table I: Characteristics of patients treated by stereotactic reirradiation using single and multiple fractions and for local failures of nasopharyngeal carcinoma

\begin{tabular}{|c|c|c|c|}
\hline & $\begin{array}{l}\text { Stereotactic radiotherapy with single } \\
\text { fraction } \\
(\mathrm{n}=43)\end{array}$ & $\begin{array}{l}\text { Stereotactic radiotherapy with multiple } \\
\text { fractions } \\
(\mathrm{n}=43)\end{array}$ & $\begin{array}{c}\text { All } \\
(n=86)\end{array}$ \\
\hline \multicolumn{4}{|l|}{ Gender } \\
\hline Male & $32(74 \%)$ & 35 (81\%) & $67(78 \%)$ \\
\hline Female & II (26\%) & $8(19 \%)$ & $19(22 \%)$ \\
\hline \multicolumn{4}{|l|}{ Age } \\
\hline$\leq 45$ & 21 (49\%) & $21(49 \%)$ & 42 (49\%) \\
\hline$>45$ & $22(51 \%)$ & $22(5 \mid \%)$ & $44(51 \%)$ \\
\hline median (range)/years & $46(32-84)$ & $46(18-69)$ & $46(18-84)$ \\
\hline \multicolumn{4}{|l|}{ Type of failure } \\
\hline Persistent disease & $19(44 \%)$ & 19 (44\%) & $38(44 \%)$ \\
\hline Recurrent disease & $24(56 \%)$ & $24(56 \%)$ & $48(56 \%)$ \\
\hline \multicolumn{4}{|l|}{ Retreatment $\mathrm{T}$ stage } \\
\hline $\mathrm{rTI}$ & $25(58 \%)$ & $23(54 \%)$ & $48(56 \%)$ \\
\hline rT2 & $5(12 \%)$ & $7(16 \%)$ & $12(14 \%)$ \\
\hline rT3 & $9(21 \%)$ & $6(14 \%)$ & $15(17 \%)$ \\
\hline rT4 & $4(9 \%)$ & $7(16 \%)$ & $11(13 \%)$ \\
\hline \multicolumn{4}{|c|}{$\begin{array}{l}\text { Time from Ist course of radiotherapy to } \\
\text { reirradiation }\end{array}$} \\
\hline$\leq 12$ months & $23(53 \%)$ & $24(56 \%)$ & 47 (55\%) \\
\hline$>12-24$ monhts & $3(7 \%)$ & $8(18 \%)$ & $11(13 \%)$ \\
\hline$>24-48$ months & $6(14 \%)$ & $6(14 \%)$ & $12(14 \%)$ \\
\hline$>48$ months & II (26\%) & $5(12 \%)$ & $16(18 \%)$ \\
\hline median (range)/months & $10(3-197)$ & $10(3-107)$ & $10(3-197)$ \\
\hline \multicolumn{4}{|l|}{ Tumor volume } \\
\hline$\leq 5 \mathrm{cc}$ & 21 (49\%) & 21 (49\%) & $42(49 \%)$ \\
\hline$>5-10 \mathrm{cc}$ & $13(30 \%)$ & $13(30 \%)$ & $26(30 \%)$ \\
\hline$>10 \mathrm{cc}$ & $9(21 \%)$ & $9(21 \%)$ & $18(21 \%)$ \\
\hline median (range)/cc & $5.1(1.3-30.7)$ & $5.6(0.8-24.7)$ & $5.2(0.8-30.7)$ \\
\hline
\end{tabular}

abnormal soft-tissue mass and/or contrast-enhancing areas as shown in axial imaging plus a margin of about 2$3 \mathrm{~mm}$. In most patients (43\%), the target was covered by single isocenter using 3 to 5 arcs of beams with a degree of 90 to 210 . Median dose was 12.5 Gy prescribed to $80 \%$ isodose line, with a range of 8 to $18 \mathrm{~Gy}$. Figure 1 shows isodose coverage of tumor in a patient treated by SRS.

SRM was performed at Sun Yat-Sen University Cancer using a commercial stereotactic radiotherapy system (Creat, China) to deliver multiple arcs of photon with a modified 8-MV linear accelerator (Elekta, Sweden). All patients were immobilized using a relocatable head ring and bracket with a plastic mask to cover whole head. Axial contrast-enhanced computed tomography (CT) scan with a slice thickness of $3 \mathrm{~mm}$ was performed for treatment planning. Majority of patients only had CT performed for localization of target/critical structures and planning since
MRI was not available in the center in Guangzhou before 2003. Target volume was defined by abnormal contrastenhanced mass plus a margin of about $2-3 \mathrm{~mm}$. The target volume was usually covered by one isocenter (98\%) using four to six arcs with a degree of $30-150$. SRT was carried out using single fraction per day and $2-3$ fractions per week, with an inter-fractional interval of at least 1 day. Median dose was 18 Gy prescribed to $90 \%$ isodose line (range: $10-24 \mathrm{~Gy}$ ) in 2 to 4 fractions for persistent disease, and $48 \mathrm{~Gy}$ to $90 \%$ isodose line (range: 20 - $49 \mathrm{~Gy}$ ) in $4-6$ fractions for recurrent disease. Figure 2 shows the isodose coverage of tumor in a patient treated by SRM.

\section{Response assessment and follow-up}

Nasopharyngoscopy +/- biopsy and imaging were performed at 8-12 weeks after treatment to document local disease status. Patients with controlled local disease were regularly followed up every 2-3 months in the first year 


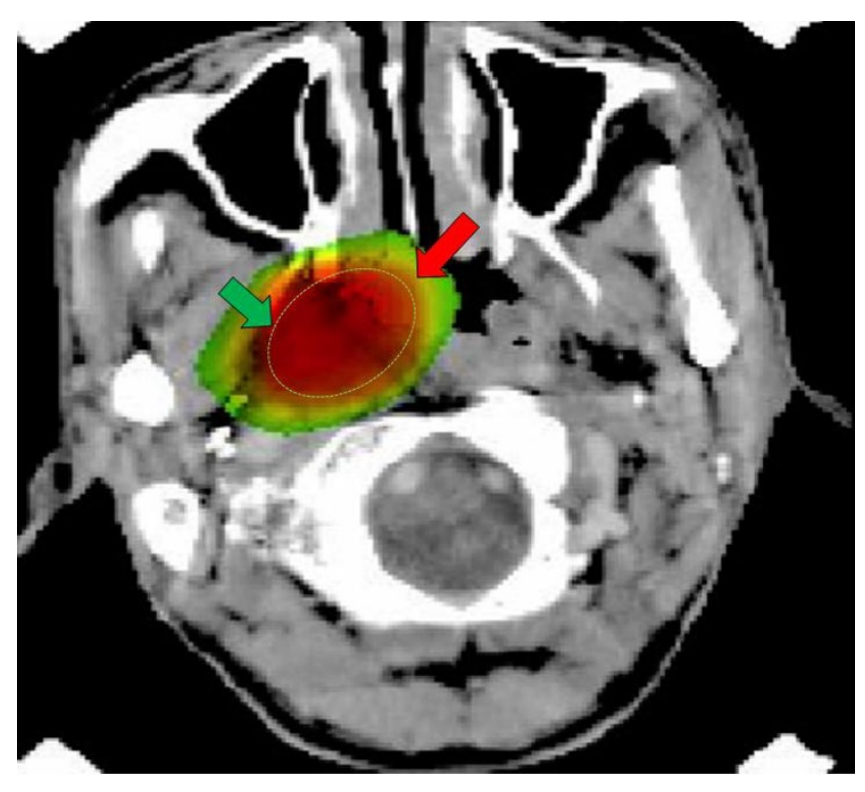

Figure I

Isodose curve showing coverage of the tumor in right side of nasopharynx in a patient treated by single fraction of stereotactic radiotherapy (target: green arrow; $\mathbf{8 0 \%}$ isodose line: red arrow).

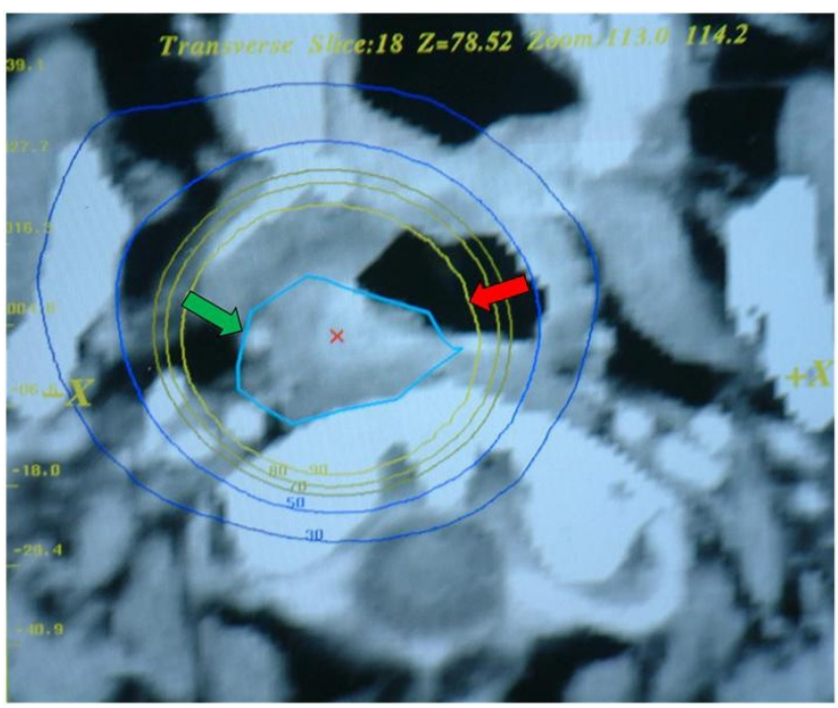

Figure 2

Isodose curve showing coverage of the tumor in right side of nasopharynx in a patient treated by multiple fractions of stereotactic radiotherapy (target: green arrow; $\mathbf{9 0 \%}$ isodose line: red arrow). and every 3-4 months thereafter. Computed tomography and/or magnetic resonance imaging were performed at least annually for 3 years after treatment.

\section{Statistical analysis}

Categorical variables were compared using chi square test or Fisher's exact test as appropriate, and continuous variables were compared using Student's t test. Treatment outcome of SRS and SRM groups were compared using the following endpoints: local failure-free rate, nodal failurefree rate, distant failure-free rate, failure-free rate and overall survival rate. The endpoints were analyzed using the product-limit method of Kaplan and Meier, and time was measured from the date of SRS or SRM until time of event occurrence, or most recent follow-up for censored observations. In patients with complete regression of disease after SRS or SRT, local failure was defined based on positive biopsy and/or radiological evidence of relapse. In patients who failed to achieve complete regression of disease after salvage treatment, local failure-free interval was set to zero. Likewise, neck node recurrence was used to define nodal failure-free rate, distant metastases was used to define distant failure-free rate, and any failure (locoregional or distant) was used to define failure-free rate. In determining overall survival rate, event was defined as deaths due to any cause. Actuarial curves were compared between SRS and SRM groups and the significance of differences was calculated using log rank test, a p value less than 0.05 was considered to be statistically significant.

\section{Results}

Tumor control and survival

Median follow-up time for surviving patients was 40 months (range: 3 - 106) after SRS and 24 months (range: 5 - 77) after SRM. Local control was significantly better in patients treated by SRM: 1- and 3-year local failure-free rates were $91 \%$ and $83 \%$ in SRM group compared with $70 \%$ and $51 \%$ in SRS group ( $\mathrm{p}=0.003$; Figure 3 ). Nodal relapse was uncommon after salvage treatment in both groups: 3-year nodal-failure free rates in SRM and SRS group were $96 \%$ and $85 \%$, respectively $(p=0.19)$. SRM group had a higher incidence of distant metastases after treatment compared with SRS group, 3-year distant failure-free rate was $69 \%$ in the former compared with $82 \%$ in the latter, but the difference was not significant ( $\mathrm{p}=$ 0.089 ). No significant difference in failure-free rate was observed between the two groups: 1- and 3-year failurefree rates were $75 \%$ and $52 \%$ in SRM group compared with $62 \%$ and $43 \%$ in SRS group ( $p=0.20)$. There was also no significant difference in overall survival between the two groups: 1- and 3-year overall survival rates were $78 \%$ and $61 \%$ in SRM group compared with $98 \%$ and $66 \%$ in SRS group ( $\mathrm{p}=0.31$; Figure 4$)$. 


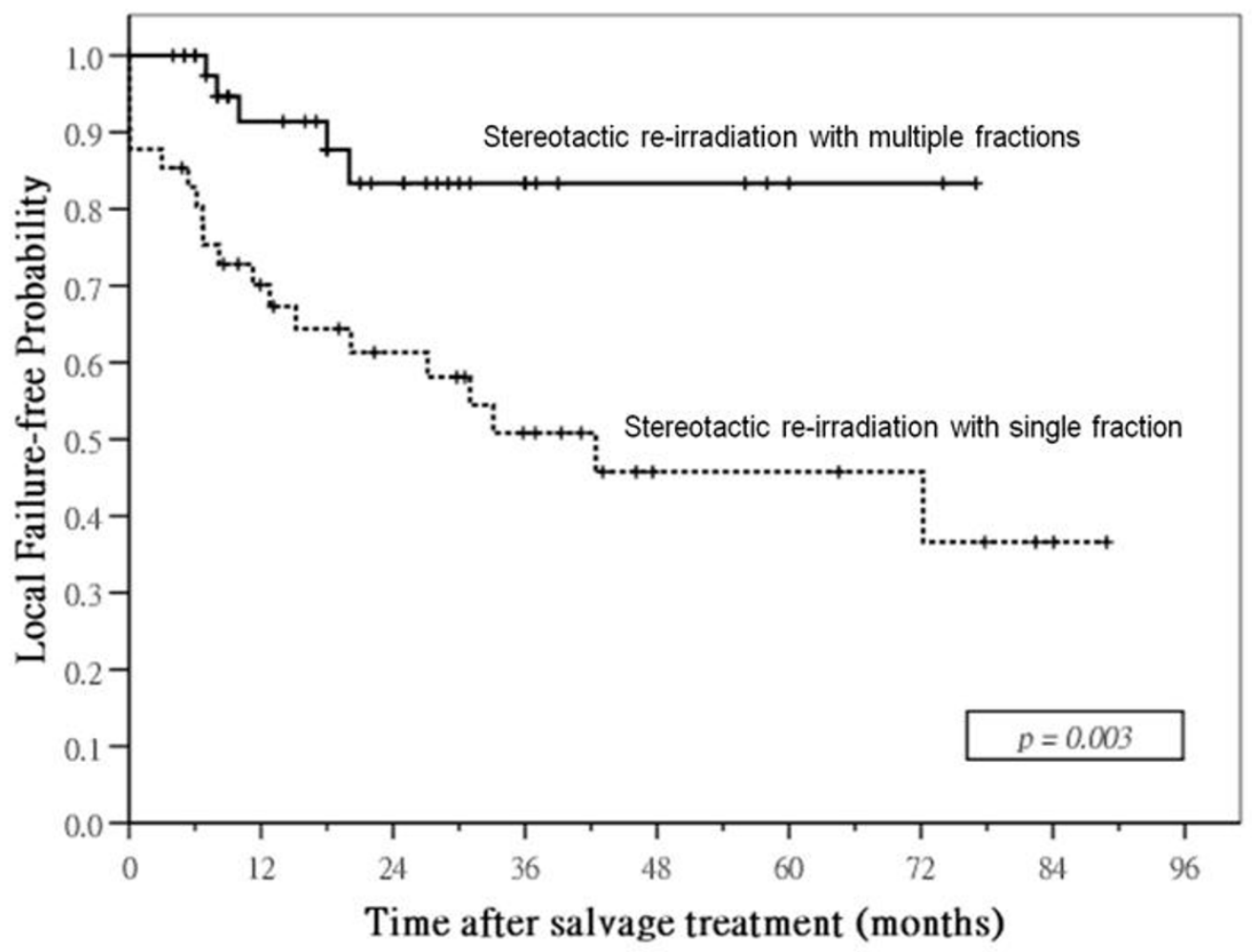

Figure 3

Local control curves. comparison of local failure-free probabilities in patients with local failures of nasopharyngeal carcinoma treated by stereotactic radiotherapy using single or multiple fractions

\section{Complications}

Both SRS and SRM were well tolerated with no severe acute complications. The incidence of severe late complications was higher in SRS group compared with SRM group (33\% vs. $21 \%$ ), although the difference was not statistical significant $(\mathrm{p}=0.22)$. Brain necrosis occurred in 7 patients after SRS (16\%) and 5 patients after SRT $(12 \%)$, with 2 fatal outcome. Massive heamorrhage occurred in 2 patients after SRS (2\%) and 1 patient after SRM (4\%), with 1 fatal outcome. Altogether there were 3 treatmentrelated deaths, all occurred in the SRM group.

\section{Subgroup analysis}

We further analyzed the outcome after SRS and SRM in different subgroups according to important prognostic factors, and the results are summarized in Table 2. The difference in local control between SRS and SRM group was mainly seen in patients treated for recurrent disease and those with disease extended beyond nasopharynx. In patients with persistent disease as well as those with disease confined to nasopharynx, there was no significant difference in local control after SRS or SRM (Figure 5 \&6). No differences in survival rates were observed in all sub- groups, including those with significant differences in local control rates favoring SRT group.

\section{Discussion}

Aggressive treatment of local failure of NPC is generally recommended since a significant proportion of patients can still be successfully salvaged and long-term survivors are not uncommon with reported 5-year survival rates ranging from 54\% after surgery [10] to $60-77 \%$ after brachytherapy $[11,12]$. Although surgery and brachytherapy can produce excellent results, only selected cases of local failure of NPC with disease confined to nasopharynx are amenable to these treatments. Most patients with local failure of NPC require external beam radiotherapy but treatment results after re-irradiation using conventional technique remained poor. The reported five-year survival rates after external reirradiation ranged from $7.6 \%$ to $36 \%$ with the use of conventional two-dimensional treatment planning and radiotherapy (6-8), and $12.4 \%$ in a mixed cohort of patients treated either with conventional twodimensional or three-dimensional conformal radiotherapy [13]. A high incidence of late complication was commonly observed after external beam reirradiation, 


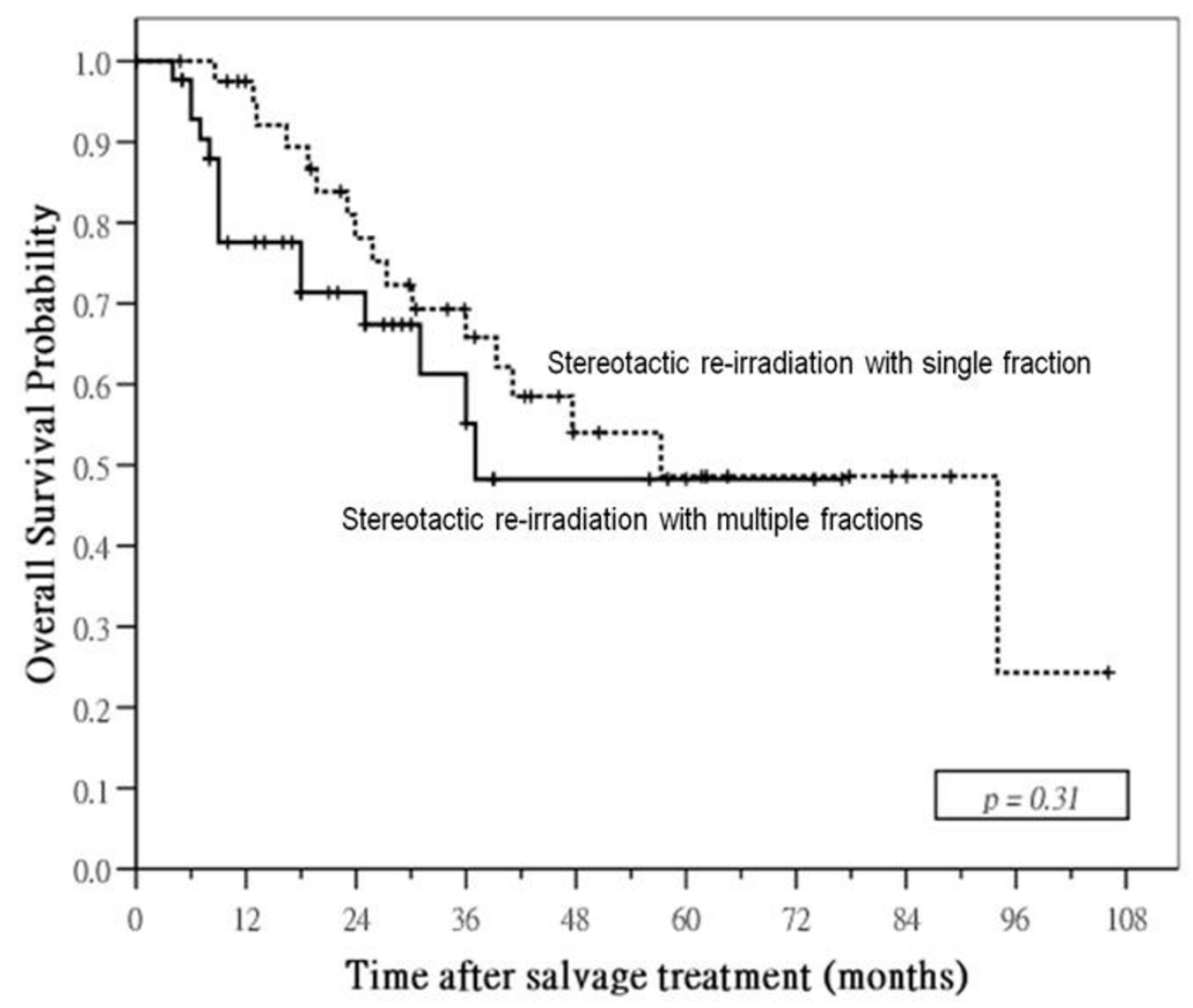

Figure 4

Survival curves: comparison of overall survival probabilities in patients with local failures of nasopharyngeal carcinoma treated by stereotactic radiotherapy using single or multiple fractions.

majority being neurological damage and soft tissue fibrosis. In a cohort of patients with local failure of NPC and all received re-irradiation by three-dimensional conformal technique, the incidence of severe late complications was still high with 5 -year actuarial incidence of $100 \%$ for $\geq$ grade 3 toxicity and $49 \%$ for $\geq$ grade 4 toxicity (9).

The concept of applying SRS in the retreatment of NPC is attractive due to the frequent involvement of intracranium and base of skull in NPC and the general radiosensitivity of the tumor. There were several published reports of retreatment of NPC by SRS and the reported tumor control rates ranged from 53 to $86 \%$ [14-20], but most of these were small series with a relatively short follow-up. In a previous report based on patients treated by SRS at Queen Mary Hospital, 5-year local failure-free and overall survival rates were $47.2 \%$ and $46.9 \%$, respectively [21]. Neuroendocrine complications occurred in $27 \%$ of patients but there were no treatment-related deaths. The results of that report compared favorably with that of gold grain implantation based on outcome of patients treated at the same institution [22].

Based on radiobiology principle, fractionation will provide better therapeutic ratio and improve treatment outcome in retreatment of NPC, and SRM has subsequently been explored as a salvage treatment for NPC. Mitsuhashi et al treated 3 patients with rT1 NPC using SRM at a dose of 50-64 Gy, and all 3 patients achieved complete response and remained free of local disease at 4-61 months [23]. The report by Mitsuhashi et al also included another patient with mucoepidermoid carcinoma of the nasopharynx treated by SRM after previous two courses of external radiotherapy, but the treatment was complicated by rupture of the internal carotid artery resulting in patient death. Using SRM at a dose of $24 \mathrm{~Gy}$ in 2 to 4 fractions, Orecchia et al reported a less satisfactory outcome in 13 patients with locally recurrent NPC, with a 3-year survival rate of $31 \%$ [24]. Ahn et al treated 12 patients with recurrent NPC by SRM using a median dose of $54 \mathrm{~Gy}$, 


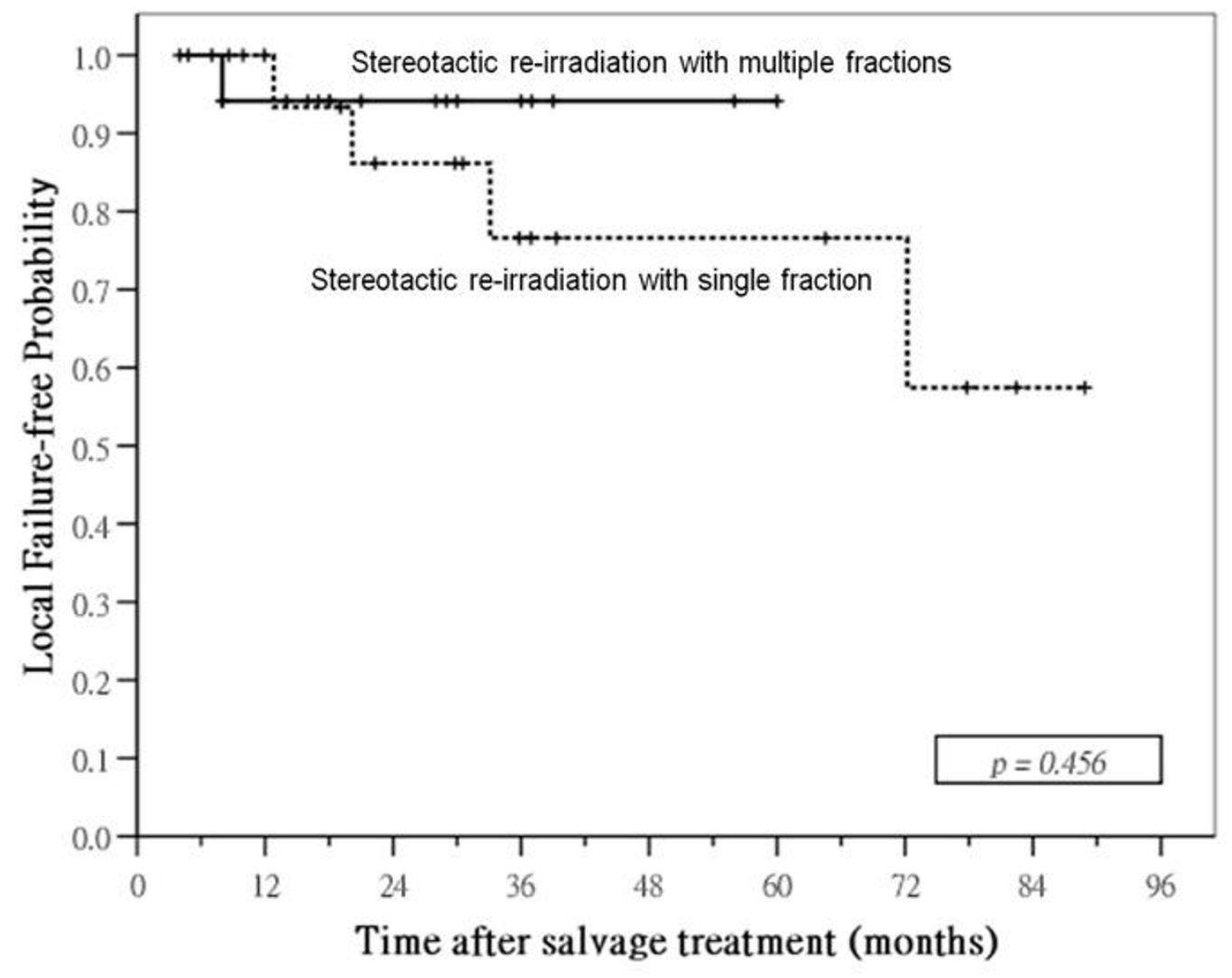

Figure 5

Persistent disease: comparison of local failure-free probabilities in subgroup of patients with persistent disease.

and reported a 2-year local control rate of 92\% [25]. Yau et al compared the outcome of 52 patients with NPC treated by either brachytherapy or SRT for persistent disease, and observed a better tumor control after SRM [26]. Xiao et al reported the outcome of 50 patients with persistent or recurrent nasopharyngeal carcinoma treated by SRM with a dose ranged from 14 to 35 Gy using a fraction dose of 5 to $15 \mathrm{~Gy}$ [27]. Of the 31 evaluable patients with persistent disease, 94\% had complete response with a one-year disease-free survival rate of $47 \%$. Eighteen patients, most of them had rT3-4 tumor, were treated for recurrent disease. The complete response rate was 56\% and 1-year disease-free survival rate was $47 \%$. In Xiao's series, however, $16 \%$ of patients treated by SRM developed fatal haemorrhage, probably due to the relatively high cumulative dose delivered. The largest published series was from the primary data set of 90 SRT patients used for the current study [28]. The reported 3-year local control rate was $89 \%$ for persistent disease and $19 \%$ for recurrent disease. Three-year disease-specific survival rate was $58 \%$. The incidence of severe late complications was $19 \%$ and there were 3 treatment-related deaths.
Based on matched-pair data from the two largest reported SRS and SRM series for NPC, we demonstrated superior tumor control with SRM, but survival rates were similar. Possible explanations include different follow-up duration in the two groups, the higher incidence of treatmentrelated deaths in SRM group, the use of additional salvage treatments, and different failure patterns. In SRM groups, no additional radiotherapy was given after local failure due to the high cumulative dose, whereas in SRS group, additional radiotherapy was given whenever possible after documented treatment failure. Thus the use of second salvage treatment may partly account for comparable survival rates in the two groups. In addition, patients in SRM group had a higher incidence of distant metastases than SRS group probably related to the percentage of higher $\mathrm{N}$ stage in the former group, and the survival benefits obtained with improved local tumor control were likely to be offset by the occurrence of distant metastases.

Late complications are common in patients receiving reirradiation for NPC. In view of the high radiation dose already received by patients during prior radiotherapy and 


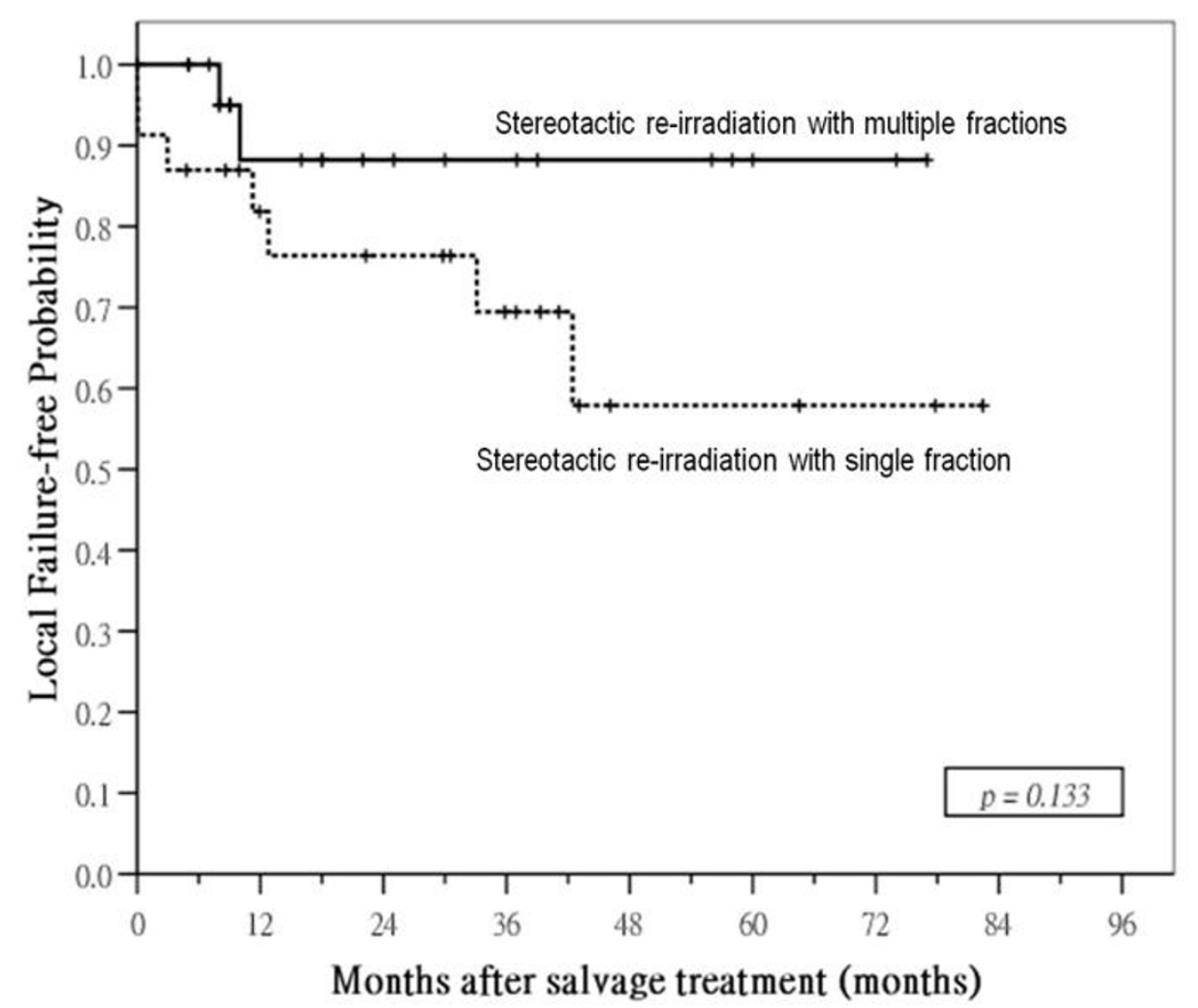

Figure 6

rTI tumor: comparison of local failure-free probabilities in subgroup of patients with disease confined to nasopharynx.

the presence of numerous nearby critical structures, it is unrealistic to expect any new form of re-irradiation to be totally risk-free. Late complications, however, differ significantly in terms of incidence and severity among different techniques of re-irradiation. In general, patients with bulky disease and tumor extended beyond nasopharynx usually have a higher incidence of late complications. When patients with similar tumor extent and size are being considered, SRS or SRM usually leads to lower incidence of late complications compared with other techniques because of high dose conformity to the target. One severe and highly fatal complication that can occur after re-irradiation is massive hemorrhage in the nasopharynx, sometimes leading to fatal outcome. The reported incidence of severe hemorrhage after SRS or SRM was relatively high compared to other re-irradiation techniques. Possible causes of severe hemorrhage after re-irradiation include mucosal necrosis, tumor progression, and carotid aneurysm. The latter one is an important cause of uncontrolled bleeding which should not be overlooked. In order to reduce the risk of hemorrhage as a result of carotid aneurysm/rupture following re-irradiation, careful selection of patients and treatment planning are important.
Patients with direct tumor encasement of cavernous sinus and internal carotid artery should not be treated by SRS, and the dose to carotid artery should be minimized in all cases. Dose per fraction is also important and most hemorrhage occurred after SRS or SRM using large fractional dose. In patients with tumor encasement of carotid artery, SRM instead of SRS should be used for reirradiation, and a small fractional dose not exceeding 6 Gy is recommended.

The superior tumor control rate achieved by SRM is likely due to the higher dose that can be delivered using this technique compared with SRS. Several reirradiation series have also recognized the important relationship between reirradiation dose and treatment outcome, although the optimal dose is not yet defined. Wang observed reirradiation dose $\geq 60$ Gy was associated with improved survival, although most patients received high dose radiotherapy in his series had rT1-2 stage [29]. Similarly, Öksüz et al also reported improved local control and survival after reirradiation with a dose of $60 \mathrm{~Gy}$ than < $60 \mathrm{~Gy}$ [30]. Lee et al also reported improved survival when a reirradiation dose > 60 Gy was used [31]. Teo et al however reported 
Table 2: Subgroup analysis of treatment outcome after stereotactic radiosurgery or radiotherapy for local failures of nasopharyngeal carcinoma

\begin{tabular}{|c|c|c|c|c|c|c|}
\hline & \multicolumn{3}{|c|}{ 3-year local failure-free rate } & \multicolumn{3}{|c|}{ 3-year overall survival rate } \\
\hline & SRS & SRM & $P$ value & SRS & SRM & $P$ value \\
\hline \multicolumn{7}{|l|}{ Sex } \\
\hline male & $54 \%$ & $87 \%$ & 0.006 & $63 \%$ & $63 \%$ & 0.806 \\
\hline female & $42 \%$ & $73 \%$ & 0.275 & $75 \%$ & $24 \%$ & 0.067 \\
\hline \multicolumn{7}{|l|}{ Age } \\
\hline$\leq 45$ & $27 \%$ & $87 \%$ & 0.023 & $63 \%$ & $44 \%$ & 0.338 \\
\hline$>45$ & $49 \%$ & $80 \%$ & 0.028 & $67 \%$ & $62 \%$ & 0.702 \\
\hline \multicolumn{7}{|l|}{ Type of failure } \\
\hline persistent disease & $77 \%$ & $94 \%$ & 0.456 & $87 \%$ & $90 \%$ & 0.589 \\
\hline recurrent disease & $30 \%$ & $75 \%$ & 0.001 & $52 \%$ & $35 \%$ & 0.419 \\
\hline \multicolumn{7}{|l|}{ rT stage } \\
\hline rTI & $69 \%$ & $88 \%$ & 0.133 & $85 \%$ & $79 \%$ & 0.721 \\
\hline rT2-4 & $28 \%$ & $78 \%$ & 0.006 & $45 \%$ & $28 \%$ & 0.458 \\
\hline \multicolumn{7}{|l|}{ Tumor volume } \\
\hline$\leq 5 \mathrm{cc}$ & $62 \%$ & $90 \%$ & 0.219 & $79 \%$ & $75 \%$ & 0.502 \\
\hline$>5-10 \mathrm{cc}$ & $61 \%$ & $67 \%$ & 0.342 & $78 \%$ & $44 \%$ & 0.117 \\
\hline$>10 \mathrm{cc}$ & $69 \%$ & $84 \%$ & 0.106 & $25 \%$ & $52 \%$ & 0.108 \\
\hline
\end{tabular}

SRS: stereotactic radiotherapy using single fracton

SRM: stereotactic radiotherapy using multiple fractions

poor survival and high incidence of complications after high dose ( $\geq 60 \mathrm{~Gy})$ reirradiation of NPC with radical intent, although the survival was still better than those treated with palliative intent using a lower dose of 40-50 Gy [32]. In all these series, retreatment was primarily carried out using conventional two-dimensional radiotherapy. In a cohort of 186 NPC patients reirradiated with either conventional or conformal radiotherapy, Chang et al observed that reirradiation dose $\geq 50$ Gy yielded better survival [13]. Using intensity-modulated radiotherapy, Lu et al [33] reported excellent local control rate after high dose (68-70 Gy) retreatment of NPC, although the follow-up time in that study was still short for evaluation of late complications. In another series of reirradiation of NPC also using intensity-modulated radiotherapy, a dose range between 50-60 Gy yielded good tumor control for rT1-3 NPC but not for rT4 disease [34]. Based on these reports, a dose of at least 50 Gy should be delivered using SRM for local failure of NPC, although the optimal fractionation schedule is still not clear. In patients with persistent disease, especially those with small volume disease confined to nasopharynx, a lower dose may be used judging from the results of SRS.

\section{Conclusion}

In conclusion, our study showed that SRM was superior to SRS in salvaging local failures of NPC, especially in patients with recurrent disease and tumor extended beyond nasopharynx. In patients with local failure of NPC, stereotactic re-irradiation using multiple fractions rather than single fraction to deliver a higher total is preferred.

\section{Competing interests}

The authors declare that they have no competing interests.

\section{Authors' contributions}

DC reviewed the treatment records, carried out statistical analysis and drafted the manuscript. SW reviewed the treatment records and assisted in manuscript preparation. VL participated in the design of the study and assisted in the statistical analysis. All authors read and approved the final manuscript. JT assisted in data analysis and drafting the manuscript.

\section{References}

I. Chua DT, Sham JS, Wei WI, Ho WK, Au GK: The predictive value of the 1997 American Joint Committee on Cancer Stage Classification in determining failure patterns in nasopharyngeal carcinoma. Cancer 200I, 92:2845-2855.

2. Cheng SH, Yen KL, Jian JM, Tsai SY, Chu NM, Leu SY, Chan KY, Tan TD, Cheng JC, Hsieh CY, Huang AT: Examining prognostic factors and patterns of failure in nasophryngeal carcinoma following concomitant radiotherapy and chemotherapy: impact on future clinical trials. Int J Radiat Oncol Biol Phys 200I, 50:717-726.

3. Au JS, Law CK, Foo W, Lau WH: In-depth evaluation of the AJCC/UICC 1997 staging system of nasopharyngeal carcinoma: prognostic homogeneity and proposed refinements. Int J Radiat Oncol Biol Phys 2003, 56:4 I 3-26. 
4. Lee AW, Sze WM, Au JS, Leung SF, Leung TW, Chua DT, Zee BC, Law SC, Teo PM, Tung SY, Kwong DL, Lau WH: Treatment results for nasopharyngeal carcinoma in the modern era: the Hong Kong experience. Int J Radiat Oncol Biol Phys 2005, 6 I: I I07- I I I6.

5. Leung TW, Tung SY, Sze WK, Wong FC, Yuen KK, Lui CM, Lo SH, $\mathrm{Ng}$ TY, O SK: Treatment results of 1070 patients with nasopharyngeal carcinoma: an analysis of survival and failure patterns. Head Neck 2005, 27:555-565.

6. Yan J-H, Hu Y-H, Gu X-Z: Radiation therapy of recurrent nasopharyngeal carcinoma: report on 219 patients. Acta Radiol Oncol 1983, 22:23-28.

7. Lee AW, Law SC, Foo W, Poon YF, Cheung FK, Chan DK, Tung SY, Thaw $\mathrm{M}$, Ho $\mathrm{JH}$ : Retrospective analysis of patients with nasopharyngeal carcinoma treated during 1976-1985: survival after local recurrence. Int J Radiat Oncol Biol Phys 1993, 26:773-82.

8. Chua DT, Sham JS, Kwong DL, Wei WI, Au GK, Choy D: Locally recurrent nasopharyngeal carcinoma: treatment results for patients with computed tomography assessment. Int J Radiat Oncol Biol Phys 1998, 41:379-386.

9. Zheng XK, Ma J, Chen LH, Xia YF, Shi YS: Dosimetric and clinical results of three-dimensional conformal radiotherapy for locally recurrent nasopharyngeal carcinoma. Radiother Oncol 2005, 75: 197-203.

10. Wei WI: Salvage surgery for recurrent primary nasopharyngeal carcinoma. Crit Rev Oncol Hemat 2000, 33:9|-98.

II. Choy D, Sham JST, Wei WI, Ho CM, Wu PM: Transpalatal insertion of radioactive gold grain for the treatment of persistent and recurrent nasopharyngeal carcinoma. Int J Radiat Oncol Biol Phys 1993, 25:505-5I2.

12. Leung TW, Tung SY, Sze WK, Sze WM, Wong VY, O SK: Salvage brachytherapy for patients with locally persistent nasopharyngeal carcinoma. Int J Radiat Oncol Biol Phys 2000, 47:405-4I2.

13. Chang JT, See LC, Liao CT, Ng SH, Wang CH, Chen IH, Tsang NM, Tseng CK, Tang SG, Hong JH: Locally recurrent nasopharyngeal carcinoma. Radiother Oncol 2000, 54:135-| 42.

14. Firlik KS, Kondziolka D, Lunsford LD, Janecka IP, Flickinger JC: Radiosurgery for recurrent cranial base cancer arising from the head and neck. Head Neck 1996, 18:160-166.

15. Miller RC, Foote RL, Coffey RJ, Gorman DA, Earle JD, Schomberg PJ, Kline RW: The role of stereotactic radiosurgery in the treatment of malignant skull base tumors. Int J Radiat Oncol Biol Phys 1997, 39:977-981.

16. Buatti JM, Friedman WA, Bova FJ, Mendenhall WM: Linac radiosurgery for locally recurrent nasopharyngeal carcinoma: rationale and technique. Head Neck 1995, 17:14-19.

17. Kocher M, Voges J, Staar S, Treuer H, Sturm V, Mueller RP: Linear accelerator radiosurgery for recurrent malignant tumors of the skull base. Am J Clin Oncol 1998, 21:18-22.

18. Cmelak AJ, Cox RS, Adler JR, Fee WE Jr, Goffinet DR: Radiosurgery for skull base malignancies and nasopharyngeal carcinoma. Int J Radiat Oncol Biol Phys 1997, 37:997-1003.

19. Chen HJ, Leung SW, Su CY: Linear accelerator based radiosurgery as a salvage treatment for skull base and intracranial invasion of recurrent nasopharyngeal carcinoma. Am J Clin Oncol 200I, 24:255-258.

20. Pai PC, Chuang CC, Wei KC, Tsang NM, Tseng CK, Chang CN: Stereotactic radiosurgery for locally recurrent nasopharyngeal carcinoma. Head Neck 2002, 24:748-53.

21. Chua DT, Sham JS, Hung KN, Leung LH, Au GK: Predictive factors of tumor control and survival after radiosurgery for local failures of nasopharyngeal carcinoma. Int J Radiat Oncol Biol Phys 2006, 66: $|4| 5-2 \mid$.

22. Chua DT, Wei WI, Sham JS, Hung KN, Au GK: Stereotactic radiosurgery versus gold grain implantation in salvaging local failures of nasopharyngeal carcinoma. Int J Radiat Oncol Biol Phys 2007, 69:469-474.

23. Mitsuhashi N, Sakurai H, Katano S, Kurosaki H, Hasegawa M, Akimoto T, Nozaki M, Hayakawa K, Niibe H: Stereotactic radiotherapy for locally recurrent nasopharyngeal carcinoma. Laryngoscope 1999, 109:805-809.

24. Orecchia R, Redda MGR, Regona R, Nassisi D, Jereczek-Fossa B, Zurrida S, Bussi M, Succo G, Sannazzari G: Results of hypofractionated stereotactic re-irradiation on 13 locally recurrent nasopharyngeal carcinoma. Radiother Oncol 1999, 53:23-28.
25. Ahn YC, Lee KC, Kim DY, Huh SJ, Yeo IH, Lim DH, Kim MK, Shin $\mathrm{KH}$, Park S, Chang SH: Fractionated stereotactic radiation therapy for extracranial head and neck tumors. Int J Radiat Oncol Biol Phys 2000, 48:50I-505.

26. Yau TK, Sze WM, Lee AW, Yeung MW, Leung KC, Hung WM, Chan WI: Effectiveness of brachytherapy and fractionated stereotactic radiotherapy boost for persistent nasopharyngeal carcinoma. Head Neck 2004, 26: 1024-30.

27. Xiao JP, Xu GZ, Miao Y]: Fractionated stereotactic radiosurgery for $\mathbf{5 0}$ patients with recurrent or residual nasopharyngeal carcinoma. Int J Radiat Oncol Biol Phys 200I, 5 I: 164-I70.

28. Wu SX, Chua DT, Deng ML, Zhao C, Li FY, Sham JS, Wang HY, Bao Y, Gao YH, Zeng ZF: Outcome of fractionated stereotactic radiotherapy for 90 patients with locally persistent and recurrent nasopharyngeal carcinoma. Int J Radiat Oncol Biol Phys 2007, 69:761-769.

29. Wang CC: Re-irradiation of recurrent nasopharyngeal carcinoma. Treatment techniques and results. Int J Radiat Oncol Biol Phys 1987, 1 3:953-956.

30. Öksüz DÇ, Meral G, Uzel Ö, Çağatay P, Turkan S: Reirradiation for locally recurrent nasopharyngeal carcinoma: treatment results and prognostic factors. Int J Radiat Oncol Biol Phys 2004, 60:388-394.

31. Lee AW, Foo W, Law SC, Poon YF, Sze WM, O SK, Tung SY, Lau WH: Reirradiation for recurrent nasopharyngeal carcinoma: factors affecting the therapeutic ratio and ways for improvement. Int J Radiat Oncol Biol Phys 1997, 38:43-52.

32. Teo PM, Kwan WH, Chan AT, Lee WY, King WW, Mok CO: How successful is high dose ( $\geq 60 \mathrm{~Gy}$ ) reirradiation using mainly external beams in salvaging local failures of nasopharyngeal carcinoma? Int / Radiat Oncol Biol Phys 1998, 40:897-9/3.

33. Lu TX, Mai WY, The BS, Zhao C, Han F, Huang Y, Deng XW, Lu LX, Huang SM, Zeng ZF, Lin CG, Lu HH, Chiu JK, Carpenter LS, Grant WH 3rd, Woo SY, Cui NJ, Butler EB: Initial experience using intensity-modulated radiotherapy for recurrent nasopharyngeal carcinoma. Int J Radiat Oncol Biol Phys 2004, 58:682-687.

34. Chua DT, Sham JS, Leung LH, Au GK: Reirradiation of nasopharyngeal carcinoma with intensity-modulated radiotherapy. Radiother Oncol 2005, 77:290-294.

Publish with Bio Med Central and every scientist can read your work free of charge

"BioMed Central will be the most significant development for disseminating the results of biomedical research in our lifetime. "

Sir Paul Nurse, Cancer Research UK

Your research papers will be:

- available free of charge to the entire biomedical community

- peer reviewed and published immediately upon acceptance

- cited in PubMed and archived on PubMed Central

- yours - you keep the copyright 